\title{
Selective metallization of alumina by laser
}

\author{
P. B. Shrivastva*, C. A. Boose and B. H. Kolster ${ }^{\dagger}$ \\ Foundation for Advanced Metals Science (SGM), P.O. Box 8039, 7550 KA Hengelo (The \\ Netherlands) \\ C. Harteveld and B. Meinders \\ Department of Physics, University of Twente, Enschede (The Netherlands)
}

(Received August 13, 1990)

\begin{abstract}
Nickel has been selectively deposited on an alumina substrate without any pretreatment from a flow of a nickel acetate solution using the focused beam of an excimer laser. Nickel spots as well as nickel lines were drawn and subsequently plated with an electroless $\mathrm{Ni}-\mathrm{B}$ coating. Excellent adhesion of the metallized layers was achieved, since with laser irradiation, both etching and deposition took place simultaneously.
\end{abstract}

\section{Introduction}

Maskless laser-induced deposition of metals on metallic and non-metallic substrates has recently become a field of growing interest [1]. Processes using laser-induced metal deposition from the gas phase $[2,3]$, solid phase [4-9] and liquid phase [10-16] have been reported. Every technique has advantages and disadvantages, depending on the application. Gas-phase deposition is limited by the availability of volatile metal-organic or inorganic materials, by unwanted side reactions which cause contamination of the metal deposits and by the need for specialized chambers [4]. Metallization from the solid or liquid phase is therefore suggested as a better alternative.

Deposition from the solid phase has been demonstrated with thin solid films of metallo-organics or organometallic components [4-9]. Copper lines have been drawn from copper acetate [5] and formate [6, 7], palladium from its acetate [8] and gold and platinum from its metallo-organic materials containing ink or resinates [4, 9]. In some cases of laser-induced deposition from thin solid films, the process is exothermic and leads to irregular line profiles. To minimize this effect and to achieve high purity, the precursor has to be tailored accordingly [9].

Deposition from the liquid phase has the advantage of being a simple technique. The precious metals gold and platinum have been deposited by

*On leave from Bhabha Atomic Research Centre, Bombay, India.

${ }^{+}$Author to whom correspondence should be addressed. 
passing a laser beam through aqueous and methanolic solutions of $\mathrm{HAuCl}_{4}$ and $\mathrm{H}_{2} \mathrm{PtCl}_{6}$ respectively [10]. Commercial electroless and electroplating gold solutions without use of external current have also been investigated for metallization [11,12]. Zahavi and coworkers [12] have successfully obtained gold features on conducting (e.g. platinum), semiconducting (e.g. silicon, $\mathrm{GaAs}$ and $\mathrm{SiC}$ ) and polymeric (e.g. polyimide) materials. However, on nonconducting substrates such as $\mathrm{Si}_{3} \mathrm{~N}_{4}$ and fused $\mathrm{SiO}_{2}$ no deposition could be achieved because of a larger band gap energy than that of the laser photon energy. The application of lasers in electroplating gold and nickel solutions with the use of an external current has been reported as a method of high speed selective maskless deposition. [13-15]. Enhancement for gold was found to be 100-fold whilst for nickel it was up to 600-fold with the use of this technique on conducting and vacuum-metallized non-conducting substrates [14].

Most of the studies in the literature deal with the deposition of metal layers either on metallic substrates or on semiconducting surfaces. Little work has been done on direct metallization of non-conducting ceramic substrates, excepting the work of Harish et al. [5], in which copper acetate was decomposed on alumina ceramic from a thin film. Metallo-organics have the advantage of decomposing at lower temperatures. There have been no reports of metallization of metallo-organics from a solution phase which would be an interesting topic to investigate.

In this paper a simple method is described for selective deposition of nickel on alumina ceramic from the liquid phase, i.e. an aqueous acetate solution. The results of laser metallization from a continuous flow of aqueous solution are presented. Metal features in the shape of nickel spots as well as line patterns were formed using the optimum conditions of fluid flow and laser power. Thin layers of deposited nickel thus formed were used as seed for electroless coatings.

\section{Experimental details}

The experimental set-up consisted of a laser system with an $X-Y$ motion and an arrangement for the substrate including a sample holder along which a continuous flow of electrolyte was pumped, as shown in Fig. 1. A xenon chloride excimer laser (Lamda Physik, Model LPX 100) producing $25 \mathrm{~ns}$. pulses at $308 \mathrm{~nm}$ was used in the study. The laser beam was focused on the substrate with a rectangular slit of size $18 \mathrm{~mm} \times 5 \mathrm{~mm}$ and with two lenses of focal lengths 500 and 2000 . The substrate used was commercial alumina of size $50 \mathrm{~mm} \times 50 \mathrm{~mm} \times 0.60 \mathrm{~mm}$, with a purity of $99.5 \%$ and of $96.0 \%$.

The ceramic was thoroughly cleaned ultrasonically in water before laser metallization. A saturated solution of A. R. grade nickel acetate was circulated over the surface of the substrate by means of a pump at a rate 


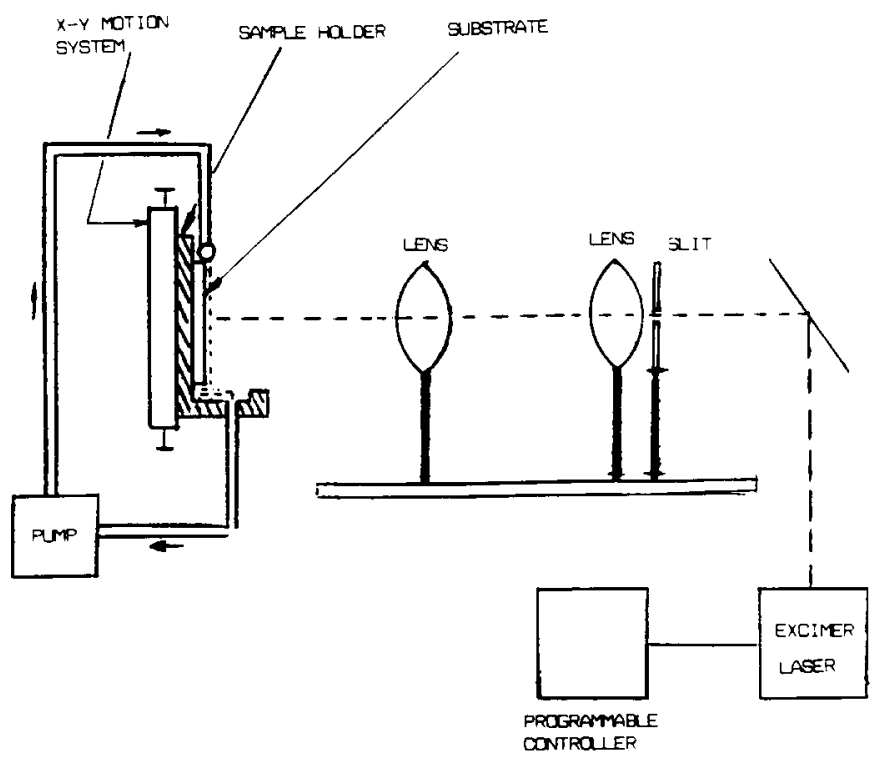

Fig. 1. Schematic diagram of experimental set-up.

of $1-1.5 \mathrm{ml} \mathrm{s}^{-1}$. The substrates were irradiated at energies ranging from 10 to $110 \mathrm{~mJ}$ pulse $\mathrm{e}^{-1}$ and at a repetition varying from 10 to $100 \mathrm{~Hz}$.

The deposited layer of nickel was cleaned thoroughly in distilled water, activated in a Puma C-12 activator (Puma Chemical Corporation, New York) and then immersed in an electroless Ni-B bath. The electroless bath consisted of nickel chloride, complexing agents and dimethylamine borane [16], and was operated at $\mathrm{pH} 6.0$ and at a temperature of $65{ }^{\circ} \mathrm{C}$ for $1 \mathrm{~h}$.

The thickness of the deposited film was measured after laser metallization and also after electroless Ni-B coating using a surface profiler (DEKTAK 3030 ) with a stylus of radius $12.5 \mu \mathrm{m}$. The structure of the deposits was studied using an optical microscope and scanning electron microscope (SEM). The presence of nickel in the metallized layer was investigated by energydispersive analysis by X-ray (EDAX). The adhesion of the deposited film after electroless plating was measured by the "tape peel off" method.

\section{Results and discussion}

\subsection{Localized metallization}

In the preliminary studies, the alumina ceramics were irradiated for spot metallization of nickel from a closed loop flow of aqueous nickel acetate solution. The laser beam was focused at a constant energy and varying repetition rates and vice versa. Better results were obtained with a lower energy and a higher repetition rate. Visible metallic layers were formed at energies of $40-60 \mathrm{~mJ}$ pulse $^{-1}$ and at frequencies of $80-100 \mathrm{~Hz}$. 


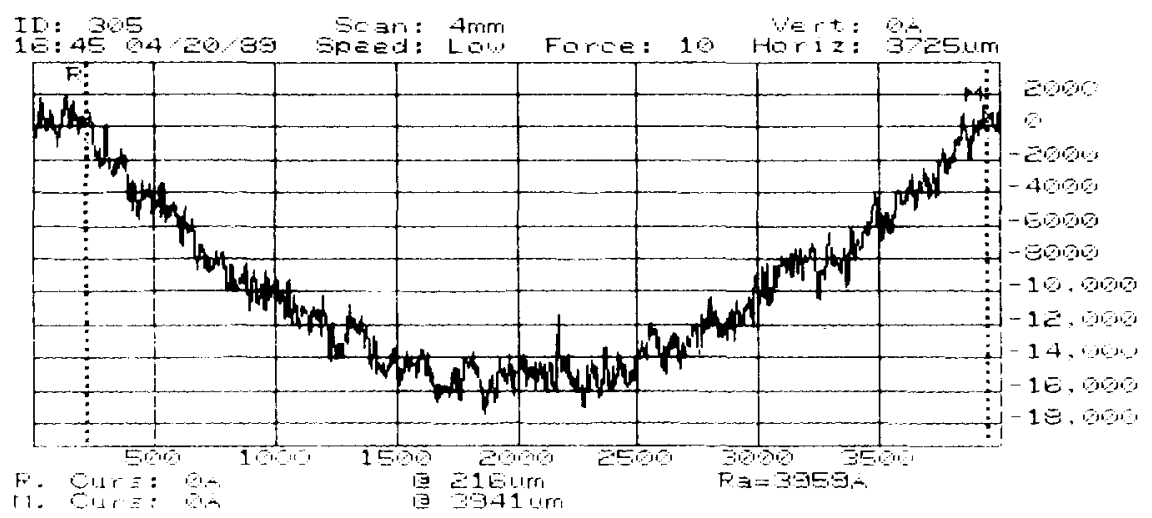

(a)

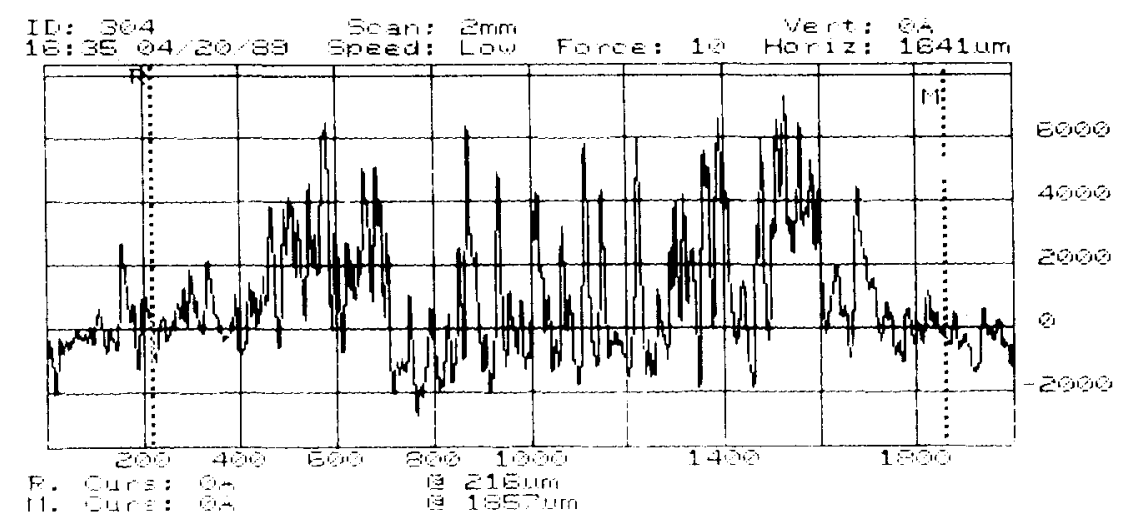

(b)

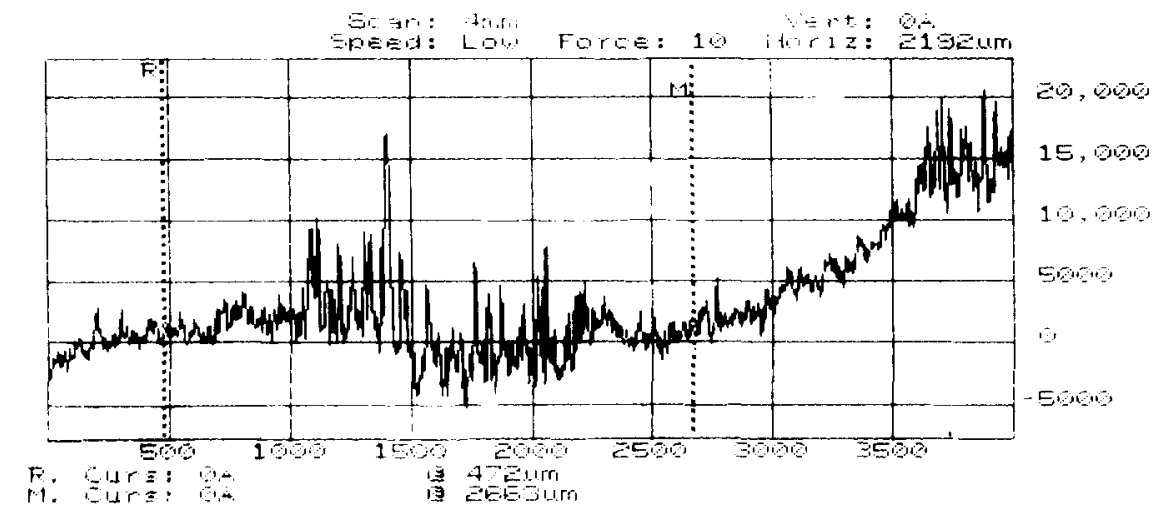

(c)

Fig. 2. Surface profile of (a) alumina ceramic surface, (b) laser-irradiated spot at $63 \mathrm{~mJ}$ pulse $\mathrm{s}^{-1}$ and (c) laser-irradiated spot at $84 \mathrm{~mJ}_{\text {pulse }}^{-1}$. 


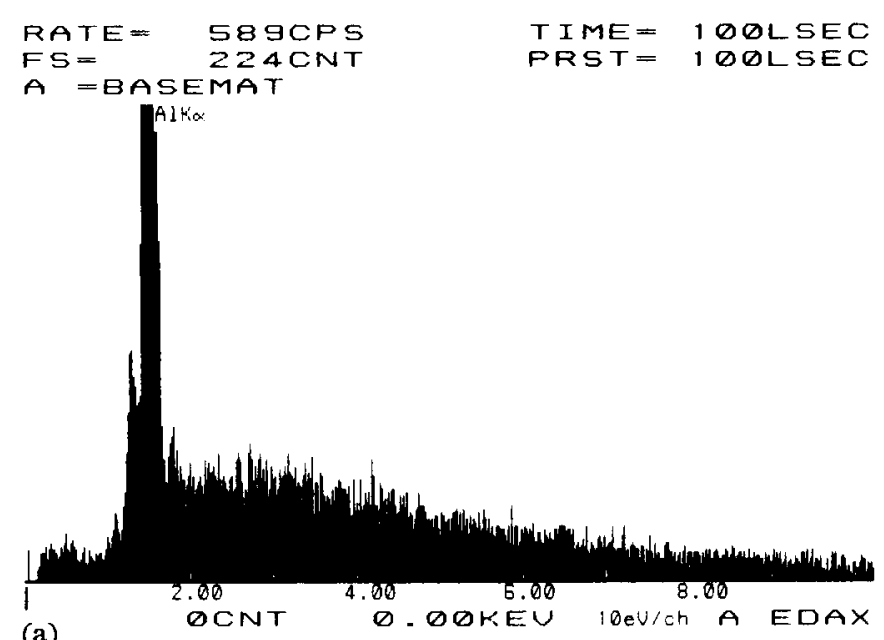

(a)

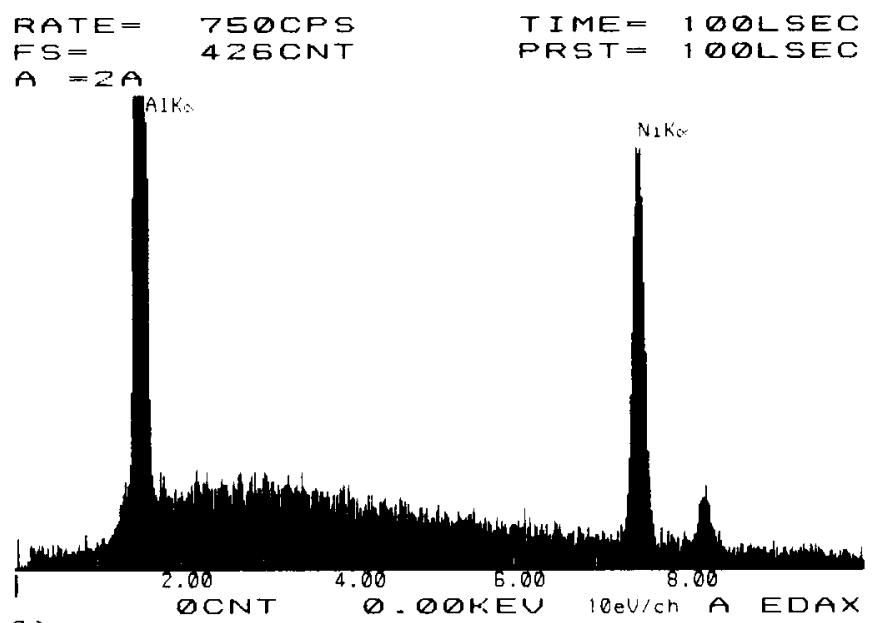

(b)

Fig. 3. EDAX analysis of (a) alumina ceramic surface and (b) metallized layer on alumina ceramic.

The results of the examination with the SEM, EDAX and surface profiler are presented in Figs. 2-4.

Figure 2 shows the surface profiles of a bare ceramic surface and the laser-irradiated spots obtained at different energies. The stylus profiler, scanning over a $4 \mathrm{~mm}$ length of the bare ceramic, revealed concavities in the surface with an average roughness of about $0.39 \mu \mathrm{m}$ (Fig. 2(a)). Upon laser irradiation at various power densities the etching of the ceramic surface and deposition of metal over the etched surface seemed to occur simultaneously. This could be clearly seen from the typical profiler plots of laserirradiated spots obtained at energies of 63 and $84 \mathrm{~mJ}^{\text {pulse }}{ }^{-1}$ (Figs. 2(b) 

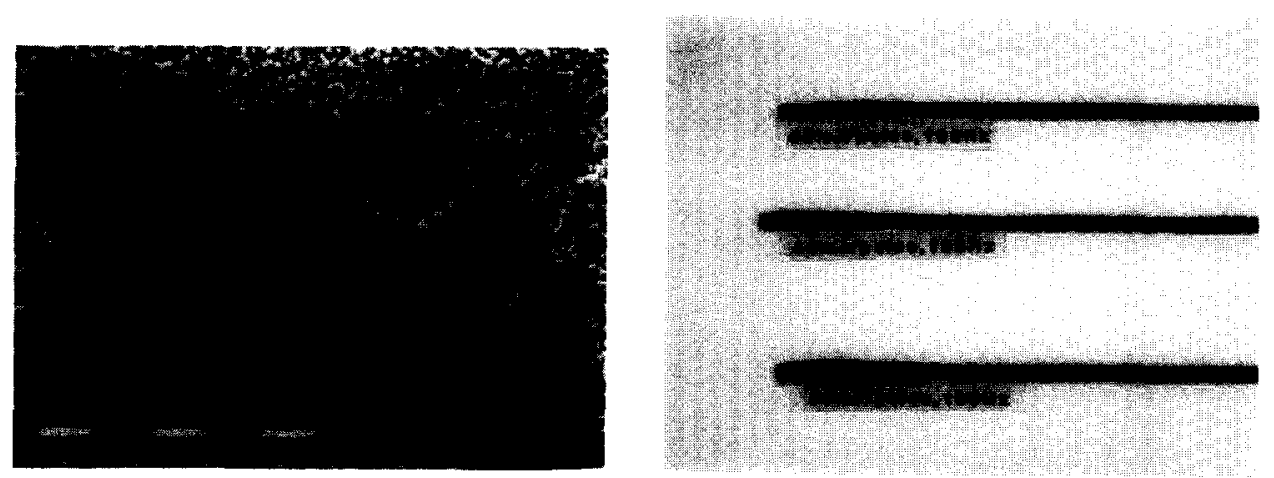

Fig. 4. SEM picture of a nickel metal layer on alumina ceramic.

Fig. 5. Nickel line drawn on alumina ceramic by laser irradiation from a flow of nickel acetate solution.

and $2(\mathrm{c})$ respectively) where irregular deposition of the metal layer occurred.

The etching of the ceramic surface by means of the laser irradiation was also studied using the stylus profiler on spots obtained separately with a flow of water instead of an aqueous nickel acetate solution. With higher power densities, i.e. 80-100 $\mathrm{mJ}_{\text {j }}$ pulse ${ }^{-1}$, deep etching of the ceramic surface up to about $3 \mu \mathrm{m}$ was observed; however, at energies of $40-60 \mathrm{~mJ}$ pulse ${ }^{-1}$ etching was less than $0.3 \mu \mathrm{m}$.

The presence of a metal layer on the irradiated spots obtained with a flow of aqueous nickel acetate solution was identified by EDAX (Fig. 3) and SEM (Fig. 4). The activated spots thus obtained were subsequently plated in an electroless $\mathrm{Ni}-\mathrm{B}$ bath, confirming the presence of nickel on the irradiated spots. The adhesion of the deposited electroless $\mathrm{Ni}-\mathrm{B}$ coating was measured by a "tape peel off" test, and it was found that all the deposited films adhered well.

\subsection{Formation of line pattern}

On the basis of the preliminary experiments the work was extended to obtain a line pattern. Initial trial runs with a higher scan rate showed no metal line, because of the ablation of the metal after deposition. However, with lower scan rates of $200-300 \mu \mathrm{m} \mathrm{s}^{-1}$ and a laser power of $40-60 \mathrm{~mJ}$ pulse $^{-1}$ at $100 \mathrm{~Hz}$, good deposits with a width of about $0.5 \mathrm{~mm}$ were obtained (Fig. 5).

The thickness of the line drawn (measured by the surface profiler) was found to vary between 0.3 and $0.6 \mu \mathrm{m}$. Subsequently, the metallized layers were plated to a thickness of about $3 \mu \mathrm{m}$ in an electroless $\mathrm{Ni}-\mathrm{B}$ bath. The adhesion of these layers, measured by the "tape peel off" method, passed the test showing good adhesion of the coatings. A surface profile and an optical micrograph of the $\mathrm{Ni}-\mathrm{B}$ coated layer are shown in Fig. 6 and Fig. 7 respectively. 


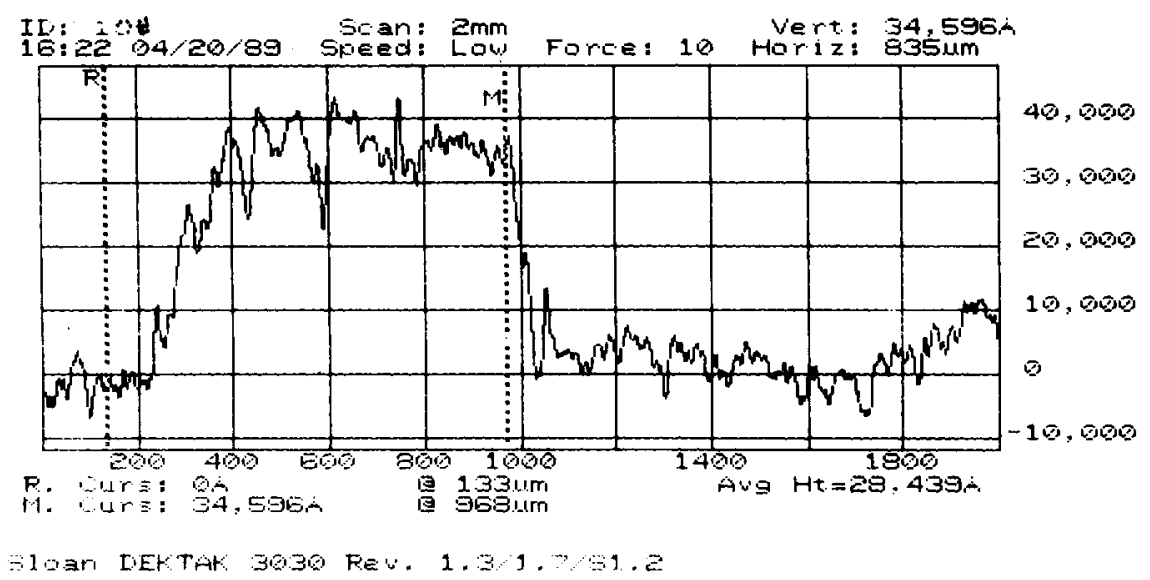

Fig. 6. Surface profile of an electroless Ni-B coating on alumina ceramic after laser metallization.

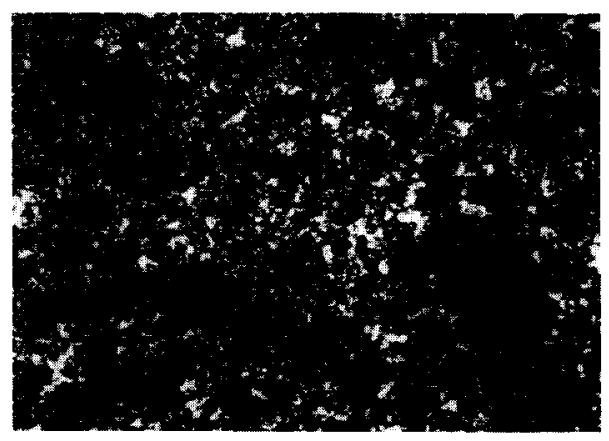

Fig. 7. Optical micrograph of an electroless Ni-B coating (original magnification $\times 100$ ).

\section{Conclusions}

Alumina ceramic was metallized selectively with a nickel layer by laser activation from a flow of aqueous nickel acetate solution. Spot metallization as well as line patterns were obtained by laser irradiation at energies of $40-60 \mathrm{~mJ}$ pulse $^{-1}$ and at a frequency of $100 \mathrm{~Hz}$. During the laser treatment etching of the ceramic surface and deposition of the metal layer occurred simultaneously, leading to excellent adhesion of the deposited layer. With the optimum power density of the laser, it is possible to control the etching of the surface to a maximum of $0.2-0.3 \mu \mathrm{m}$.

The extent of deposition of the metal layers depended on the duration of irradiation. In the system under study, nickel layers of $0.3-0.6 \mu \mathrm{m}$ were achieved, which were successfully used as seed for electroless Ni-B plating. Since no pretreatment of the ceramic surface is required, this process can be suggested as a simple technique for metallization. 
Work is in progress aimed at producing very thin line patterns with a faster scan rate. In addition, metallization with other metallo-organic compounds from a flow of aqueous solution is also in progress. The results will be presented soon.

\section{Acknowledgments}

The authors would like to thank C. B. Jongeling, H. Hulleman, W. H. $\mathrm{J}$. Bruis and J. Jansen for their suggestions and measurements.

\section{References}

1 D. Bäuerle, Chemical Processing with Lasers, Vol. 1, Springer Series on Material Science, Springer, Berlin, 1986.

2 D. J. Ehrlich and J. Y. Tsao, J. Vac. Sci. Technol. B, l (1983) 969.

3 B. Markwalder, M. Widmer, D. Braichotte and H. van den Bergh, J. Appl. Phys., 65 (1989) 2470.

4 R. C. Sausa, A. Gupta and J. R. White, J. Electrochem. Soc., 134 (1987) 2707.

5 C. M. Harish, V. Kumar and A. Prabhakar, J. Electrochem. Soc., 135 (1988) 2903.

6 A. Gupta and R. Jagannathan, Appl. Phys. Lett., 51 (1987) 2254.

7 P. Hoffmann, B. Lecohier, S. Goldoni and H. van den Bergh, Appl. Surf. Sci., 43 (1989) 54.

8 M. E. Gross, A. Appelbaum and P. K. Gallagher, J. Appl. Phys., 61 (1987) 1628.

9 M. E. Gross, G. J. Fisanick, P. K. Gallagher, K. J. Schnoes and M. D. Fennell, Appl. Phys. Lett., 47 (1985) 923; M. E. Gross, A. Appelbaum and K. J. Schnoes, J. Appl. Phys., 60 (1986) 529.

10 R. F. Karlicek, V. M. Donnelly and G. I. Collins, J. Appl. Phys., 53 (1982) 1084.

11 H. R. Khan, M. U. Kittel and Ch. J. Raub, Plat. Surf. Finish., 75 (1988) 58.

12 J. Zahavi, S. Tamir and M. Halliwell, Plat. Surf. Finish., 73 (1986) 57; J. Zahavi, S. Tamir, M. Rotel, G. J. Campisi, M. Halliwell and P. E. Pehrsson, in Proc. 12th World Congr. on Surface Finishing, Interfinish '88, Association Française des Ingénieurs et Techniciens de l'Electrolyse et des Traitements de Surface, 1988, p. 329.

13 R. J. von Gutfeld, E. E. Tynan, R. L. Melcher and S. E. Blum, Appl. Phys. Lett., 35 (1979) 651. R. J. von Gutfeld, M. H. Gelchinski, L. T. Romankiw and D. R. Vigliotti, Appl. Phys. Lett., 43 (1983) 876.

14 C. Bocking, Trans. Inst. Met. Finish., 66 (1988) 50.

15 M. Fujita, M. Kobayash and S. Hoshinouchi, in Proc. 12th World Congr. on Surface Finishing, Interfinish '88, Association Française des Ingénieurs et Techniciens de l'Electrolyse et des Traitements de Surface, 1988, p. 203.

16 P. B. Shrivastva, Ph.D. Thesis, Indian Institute of Technology, Bombay, 1986. 